\title{
Exército, Nação e Saúde: A medicina militar brasileira como elemento de criação de fronteira nacionais
}

\author{
Ejército, la nación y la salud: La medicina militar brasileña como \\ elemento de frontera nacional de la creación \\ Army, Nation and Health: Brazilian military medicine as element of \\ creation of national borders
}

\author{
Me. Tiago Vicente Penteado Bomfim ${ }^{1}$ \\ Dr. Vanderlei Sebastião de Souza² \\ Me. Wagner Henrique N. Fiuza ${ }^{3}$
}

\begin{abstract}
Resumo
Pretendemos a partir deste texto investigar e analisar, a atuação do médico e higienista do exército brasileiro Arthur Lobo da Silva, como produtor do conhecimento cientifico da área da saúde desta instituição, entre os anos de 1920 a 1940. Do mesmo modo, será preciso entender de que maneira a medicina militar se constituiu como um elemento criador de fronteira no início do século XX. A participação de Arthur Lobo da Silva nestes campos foi materializada em diversas publicações como jornais, periódicos, entre outros. Tais obras servirão de componente básico para analise deste trabalho. Destaca-se que as ideias do autor sobre higiene, saúde, e o papel do exército nos permitirão compreender a sua representação de nação, fronteira e região e o que este autor acredita ser o papel do Estado brasileiro no período. Ao expor tais opiniões e posicionamentos Arthur Lobo da Silva ira se inserir no debate com outros intelectuais brasileiros, a respeito dos problemas sanitários do país o que inviabilizava no período a criação de uma "nação", "fronteira" e de um "povo brasileiro", a inserção destes militares nesta discussão legitimou o papel do Exército como uma das soluções sociais para estes problemas. Para fazer tal analise, além de utilizar algumas publicações de Arthur Lobo da Silva, em periódicos militares e civis, os livros A luta contra as moléstias venéreas no Exército brasileiro (1929), O serviço de saúde do Exército brasileiro (1958), Antropologia no Exército brasileiro (1929), também serão utilizados para mapear a sua trajetória intelectual.
\end{abstract}

Palavras-Chave: Exército, fronteira, medicina militar, saúde.

\section{Resumen}

Tenemos la intención de investigar y analizar a partir de este texto, el papel del médico y el ejército brasileño Arthur higienista Lobo da Silva, como productor de conocimiento científico de la salud de esta institución, entre los años 1920 a 1940. Del mismo modo, es necesario entender la forma en la medicina militar constituye como un elemento creativo frontera a principios del siglo XX. La participación de Arthur Lobo da Silva en estos

\footnotetext{
${ }^{1}$ Mestre História pelo Programa de Pós-Graduação em História da Universidade Estadual do Centro Oeste (UNICENTRO), Guarapuava, Paraná, Brasil. tiagobomfimunicentro@gmail.com

2 Pós-Doutor em História das Ciências; Professor Adjunto do Departamento de História da Universidade Estadual do Centro-Oeste (UNICENTRO-PR) e do Programa de Pós-Graduação em História pela mesma instituição, Guarapuava, Paraná, Brasil. vanderleidesouza@yahoo.com.br

${ }^{3}$ Mestre em História pelo Programa de Pós-Graduação em História da Universidade Estadual do Centro Oeste (UNICENTRO), Guarapuava, Paraná, Brasil. wagnerunicentro@ hotmail.com
} 
campos se ha materializado en varias publicaciones tales como periódicos, revistas, entre otros. Estas obras servirán como un componente básico para el análisis de este trabajo. Es de destacar que las ideas del autor sobre la higiene, la salud y la función del ejército nos permitirán entender su representación nación, frontera y la región y lo que el autor cree que es el papel del Estado en el período. Al exponer estos puntos de vista y posiciones Arthur Wolf ira Silva entrar en el debate con otros intelectuales brasileños, sobre los problemas de salud del país que impidió el período de la creación de una "nación", "frontera" y un "pueblo brasileño", la inclusión de estos militares esta discusión legitima el papel del ejército como soluciones a estos problemas sociales. Para hacer este análisis, además de utilizar algunas publicaciones de Arthur Lobo da Silva, en los periódicos militares y civiles, los libros La lucha contra las enfermedades venéreas en el Ejército de Brasil (1929), el servicio de salud del Ejército de Brasil (1958), Antropología en ejército de Brasil (1929), también se utiliza para mapear su trayectoria intelectual.

Palabras claves: Ejército, la frontera, la medicina militar, la salud.

\begin{abstract}
We intend from this text to investigate and analyze the work of the physician and hygienist of the Brazilian army, Arthur Lobo da Silva, as a producer of the scientific knowledge of the health area of this institution, between the years of 1920 and 1940. Likewise, In what way military medicine became a frontrunner in the early twentieth century. The participation of Arthur Lobo da Silva in these fields was materialized in several publications such as newspapers, periodicals, among others. Such works will serve as a basic component for the analysis of this work. It should be noted that the author's ideas on health, hygiene, and the role of the army will allow us to understand his representation of nation, frontier and region and what this author believes to be the role of the Brazilian State in the period. In exposing such opinions and positions Arthur Lobo da Silva will be inserted in the debate with other Brazilian intellectuals regarding the health problems of the country which made it impossible in the period to create a "nation", "frontier" and a "Brazilian people", The insertion of these military personnel in this discussion legitimized the role of the Army as one of the social solutions to these problems. To make such an analysis, in addition to using some publications of Arthur Lobo da Silva, in military and civil journals, the books The fight against venereal diseases in the Brazilian Army (1929), The health service of the Brazilian Army (1958), Anthropology in the Brazilian Army (1929), will also be used to map their intellectual trajectory.
\end{abstract}

Keywords: Army, border, military medicine, health.

\title{
1. Introdução
}

Nos últimos anos temas como saúde, genética, eugenia e raça, estão (re)aparecendo em trabalhos com novos problemas e novas propostas, o que nos abre a possibilidade para diferentes abordagens sobre as fontes. Em pesquisas referentes à formação nacional e também a construção de fronteiras, tanto no final do período Imperial e início do período Republicano quanto na "Era Vargas", a historiografia vem apontando para a importância do tema da saúde para esta discussão. Novas instituições e personagens vêm sendo utilizados para repensar estes acontecimentos, no qual novos horizontes abriram-se para a produção historiográfica a respeito da História das Ciências, sobretudo das ciências biomédicas.

De acordo com a historiografia (HOCHMAN, 2004; LIMA, 1996; MAIO, 1996; SCHWARCZ, 1993), passados alguns anos do advento da proclamação da República em 1889, o Brasil ainda era representado pelos intelectuais como uma nação que possuía as suas fronteires em processo de construção. Com uma constituição social marcada por uma extensa população miscigenada, na qual negros, indígenas e sertanejos habitavam o desconhecido 
interior brasileiro, passando por imensas dificuldades econômicas, além de serem "marginalizados" por um modelo de governo federalista ineficiente, sofriam com as inúmeras doenças que assolavam estas regiões rurais (SOUZA, 2006).

Para solucionar estes problemas diversas instituições estiveram imersas no processo que culminou na higienização da sociedade. Procurando legitimar seu discurso perante estas diferentes áreas envolvidas no debate estava o exército. A partir dos anos de 1970 a historiografia vem apontando cada vez mais para a influência dos militares para a criação e posteriormente para a manutenção da República. O fato de estes militares circularem pelos cargos de poder na República, fez com que as ideias discutidas no interior da instituição fossem amplamente divulgadas para a maior parte do país (ALVES, 2003).

Além dos eventos científicos serem um dos mecanismos de divulgação das pesquisas cientificas, os periódicos militares foram amplamente utilizados como meio de legitimação da atuação dos médicos do Serviço de Saúde desta instituição. No próximo item, minha preocupação consistirá exatamente em analisar como a medicina militar se construirá como saber cientifico capaz de auxiliar no processo de construção de fronteiras e nação, tendo em vista a análise do processo no qual a medicina militar deixa de ser um conhecimento voltado somente para o combate as doenças situadas no exército, para torna-se conhecimento capaz de curar as doenças espalhas pelo Brasil, além de ser fator importante para o projeto de saneamento e construção da nação brasileira.

\section{A medicina militar e a medicina tropical: um ideal de fronteira}

O Brasil e outras nações mundiais viviam em clima de otimismo científico, principalmente no campo médico, a transição do século XIX para o XX, foi o desabrochar da chamada "medicina dos climas quentes" (LÖWY, 2006). Esta área da medicina preocupavase em estudar as doenças que se propagavam em países de clima tropical. Em um primeiro momento, embasados nos conhecimentos de Louis Pasteur e Robert Koch, que teorizavam a ação dos microrganismos como causadores de doenças, grande parte do campo médico acreditavam que tanto a febre amarela como também a malária seriam doenças contagiosas, que poderiam se propagar pelo ar ou contato com o indivíduo doente, ou até mesmo pelo contato com as suas roupas, cama, e até mesmo alimentos contaminados (LÖWY, 2006, p.13).

Segundo Simone Kropf, o marco fundamental para à afirmação da abordagem insetovetor no campo da medicina tropical "se deu com a elucidação do modo de transmissão 
daquela que era considerada a doença tropical por excelência: a malária" (KROPF, 2009). A descoberta da causa da malária foi anterior a da febre amarela, somente em 1881 foi descoberta a partir das pesquisas de Carlos Finlay que a transmissão do paludismo, nome também dado à malária, em humanos ocorria pela picada de mosquitos do gênero Anopheles (SILVA, J., 2000). Em meados de 1900 a 1901, pesquisadores puderam concluir através de pesquisas, que a febre amarela, assim como a malária também era transmitida por mosquitos contaminados (LÖWY, 2006, p.13).

A identificação dos mosquitos causadores destes males deu início a um projeto de pesquisas relacionadas às doenças encontradas em climas tropicais, tendo como cerne o modelo do parasito-vetor, e que segundo Simone Kropf "se reportava a um conjunto particular de enfermidades [...] causadas por protozoários ou helmintos” (KROPF, 2009, p,73). Pioneira neste assunto, conforme destaca Kropf (2009) no início do século XX a Inglaterra inserida no contexto imperialista, teve como preocupação enfrentar as doenças encontradas em suas colônias na África e Ásia, o que levou a criação das escolas de medicinas especializadas no estudo e também combate e prevenção as doenças incorporadas nesta medicina tropical (KROPF, 2009).

A importância dada a estas doenças pelos médicos europeus e norte-americanos originam-se a partir das expansões imperialistas destes países (CARDOSO, 2013, p. 76). Ao entrar em contato com territórios que ainda não haviam sido explorados, descobriu-se uma nova gama de doenças que afetavam principalmente os soldados que haviam sido designados para executar missões nestas novas colônias. A grande mortalidade que ocorria tanto com os soldados como também com aventureiros que viajavam para os trópicos ${ }^{4}$ despreparados para as condições que iriam encontrar, despertou a preocupação do campo médico destas nações atingidas.

No Brasil, esta preocupação com as "doenças de clima quente", também constituiu um avanço nas pesquisas médicas, como destaca Simone Kropf "logo após a fundação das escolas inglesas de medicina tropical cogitou-se criar, nas faculdades de medicina do Rio e da Bahia,

\footnotetext{
${ }^{4}$ Para mais informações sobre estudos envolvendo a ideia de trópicos ver: ARNOLD, David. "Inventing tropicallity". In: The problem of nature: environment, culture and European expansion. Blackwell Publishers, Oxford/Cambridge, 1996, p.141-168. HARRISON, Mark. "Health, Race, Environment and British Imperialism". In: Climates and Constitutions: Health, Race, Environment and British Imperialism in India. Oxford: Oxford University Press, 1999. McLEOD, Roy. "Introduction". In: McLEOD, Roy \& LEWIS, Milton (eds.). Disease and Empire. Perspectives on Western medicine and the experience of European expansion. London, Routledge, 1988. ANDERSON, Warwick. "Introduction", "American Military Medicine faces West". Colonial Pathologies. American Tropical Medicine, Race and Hygiene in the Philipines. Durham/London: Duke University Press, 2006
} 
uma cátedra de "patologia tropical" (KROPF, 2009, p.75). Esta proposta criada por Carlos Seidl em maio de 1900, chegou a ser discutida no IV Congresso Brasileiro de Medicina e Cirurgia, mas como retrata a autora, esta ideia não foi levada adiante sendo derrotada em votação neste evento (KROPF, 2009).

Conforme Kropf (2009) destaca o mundo cientifico ficou marcado na virada do século XIX para o XX, pela busca dos transmissores alados para as doenças, especialmente os mosquitos. Enquanto em Manguinhos, Oswaldo Cruz coletava e classificava insetos pelo Brasil, as pesquisas dos cientistas brasileiros reproduziam uma pratica comum entre os microbiologistas e médicos europeus. Da mesma forma que estes sujeitos se deslocavam para as colônias africanas e asiáticas, com o objetivo de combater as epidemias e estudar as doenças tropicais, os pesquisadores do instituto de Manguinhos cada vez mais adentravam o interior do Brasil afim de se inserirem no campo das pesquisas envolvendo o combate as doenças de climas quentes (KROPF, 2009).

Em abril de 1909, Carlos Chagas (1878-1934), divulgou a sua principal descoberta, além de identificar o patógeno da doença que levou o nome de Trypanosoma Cruzi, ele também divulgou o responsável pela transmissão, o mosquito Triatoma Infestans, também conhecido como barbeiro. Após identificar esta nova doença tropical Carlos Chagas a nomeou com seu sobrenome passando a se chamar doença de chagas (DIAS, 1997).

Como pesquisador do Instituto Oswaldo Cruz, Carlos Chagas ao se aprofundar em pesquisas referentes ao Trypanosoma Cruzi, fez grandes contribuições para o debate cientifico que acontecia em várias nações da Europa, nos Estados Unidos e também nos países latinoamericanos sobre as doenças tropicais. No Brasil esta descoberta impulsionou o amplo debate sobre as condições sanitárias do país, principalmente com as populações que habitavam em seu interior (KROPF, 2009). Para compreendermos a preocupação das autoridades em despertar na população brasileira o cuidado e a importância de prevenir certas doenças, retomamos novamente ao discurso de Miguel Pereira em outubro de 1916.

Ao discursar na recepção a Aloysio de Castro, diretor da Faculdade de Medicina do Rio de Janeiro, que havia recém-chegado de uma viagem que havia feito para a Argentina (SÁ, 2009), Miguel Pereira demarcava sua posição contrariando aqueles que não acreditavam na influência negativa das doenças que afetavam a população que habitava no interior do país (SÁ, 2009, p.334). Miguel Pereira recorreu a sua "autoridade" de medico-pesquisador que havia visitado os sertões brasileiros e presenciado as péssimas condições em que se encontravam as pessoas destas regiões afastadas dos centros urbanos, para apresentar aos seus pares que a malária, a sífilis, o alcoolismo, o abandono e também a fome eram os principais 
formadores desta "legião de inválidos", frase ressaltada por Miguel Pereira em seu discurso (SÁ, 2009). Este discurso havia sido realizado em um primeiro momento para um grupo restrito de pessoas, porém, as frases ditas por Miguel Pereira geraram assuntos em diversos jornais do período, dentre eles citamos Jornal do Commercio, um dos jornais que possuía grande visibilidade no Rio de Janeiro.

Como podemos ver, as doenças tropicais além de suscitar o debate em prol do saneamento do Brasil, também gerou o debate em torno da construção das fronteiras e da nacionalidade brasileira. Dominichi de Sá afirma que além de reiterar as denúncias sobre a condição da população do interior do Brasil, o discurso de Miguel Pereira teria sido uma resposta ao Deputado federal Carlos Peixoto (1871-1917), que afirmava quando questionado sobre o conflito mundial, que a população não deveria sentir temor, pois era somente ir aos sertões e convocar os caboclos que lá habitavam para o exército, que de prontidão eles iriam defender o país (SÁ, 2009, p.336). Se na Europa a preocupação com as doenças tropicais, tem como origem a mortandade dos soldados nas colônias, no Brasil a preocupação com as doenças tropicais inicia com os cuidados das populações do interior, e que de certa forma, também iriam fazer parte do exército.

\subsection{Exército como fator de aglutinação do território nacional}

Como bem vimos até o momento, as expedições ao interior do país permitiram com que a classe medica ganhasse maior autoridade nos debates públicos sobre os problemas nacionais. Outra instituição que se beneficiou destas expedições foi o exército. Conforme destaca Nísia Trindade Lima, no momento das chamadas missões civilizatórias da Republica, tanto as viagens cientificas, como as expedições militares e incursões ao interior, foram fundamentais para alcançar os objetivos estratégicos como as construções de linhas telegráficas e ferroviárias, além das ações profiláticas e de conhecimentos científicos dos vastos territórios, até então desconhecidos pelo Estado brasileiro (LIMA, 1999, p.57).

Para esta autora, a visão romancista do período creditava mais outra função para as expedições militares, que seria a perspectiva otimista de integração nacional (LIMA, 1999, p.65). Nesta lógica, "o exército teria o papel de agente de socialização do sertanejo" (LIMA, 1999, p.65), ou seja, a partir do momento em que o exército reunisse homens do sertão recrutados como soldados comuns, também agregando os oficiais educados nas cidades litorâneas, o exército vincularia o sertão e o litoral, o que auxiliaria a resolver os quatros temas presentes em diferentes documentos das três primeiras décadas do século XX e 
debatidos pela intelectualidade brasileira: "Sertão, povoamento, civilização e integração a nacionalidade" (LIMA, 1999, p.65).

Como podemos ver tanto na Europa como também no Brasil, o exército era imprescindível para que fosse possível concretizar o projeto de entrada destas comitivas medicas ou com funções urbanísticas ao interior de certas regiões consideradas de difícil acesso para o Estado naquele momento (LIMA, 1999). Como representante do exército nas discussões envolvendo saúde, higiene e a construção da nacionalidade brasileira no início do século XX Arthur Lobo médico do exército brasileiro discorreu sobre a importância do exército para a constituição e legitimação das fronteiras brasileiras.

Nascido em 21 de abril de 1873, na região de Pernambuco, Arthur Lobo formou-se em medicina pela Faculdade de Medicina do Rio de Janeiro em 1896. Grande parte de sua atuação no exército foi dedicada aos serviços médicos em hospitais e juntas de saúde de várias regiões do país. Como médico, atuou no Hospital Central do exército nos anos de 1901, 1904 e 1912. Já no Hospital Militar de Manaus, atuou como médico no ano de 1905, e no Hospital Militar do Recife em meados de $1907^{5}$.

Como "cientista militar", Arthur Lobo da Silva publicou um conjunto de obras sempre relacionadas às questões de higiene, doenças, antropologia e também estatísticas sobre os militares que ingressavam no serviço militar. Entre as suas principais obras podemos citar $A$ luta contra as moléstias venéreas no exército brasileiro (1929); Perigo Social da Syphilis (1906); O serviço de Saúde do Exército brasileiro (1958).

Além destes livros, Arthur Lobo publicava com bastante frequência em periódicos militares, o que foi fundamental para a divulgação e ampliação dos estudos sobre o campo da medicina militar. A frequência de publicação de Arthur Lobo nestes periódicos também é um indicativo do grau de autoridade que este médico veio assumindo ao longo do tempo.

Arthur Lobo médico e representante do Serviço de Saúde do exército, defendeu o papel do médico e da medicina como fatores de legitimação e demarcação de fronteiras, devido ao trabalho que estes médicos desempenhavam, conforme destaca Lobo: "que em todas estas tarefas, lá se encontrava o médico, acompanhando o seu batalhão, e lutando sempre pela conservação da saúde do seu pessoal" (SILVA, A., 1956, p.211). A partir disto, trabalhamos com a hipótese que devido ao exército estar envolvido com a descoberta das

\footnotetext{
${ }^{5}$ Sobre Arthur Lobo estas informações biográficas foram retiradas do texto: DO "EXÉRCITO DE SOMBRAS" AO "SOLDADO-CIDADÃO": SAÚDE, RECRUTAMENTO MILITAR E IDENTIDADE NACIONAL NA REVISTA NAÇÃO ARMADA (1939-1947), produzido em 2010, cuja autoria é de Vitor José da Rocha Monteiro.
} 
doenças de clima tropical, esta instituição passa a ter legitimidade para abordar estes assuntos, sendo marcante nos anos de 1900 a 1940, o número de pesquisas feitas por médicos do exército.

Assim como as bases cientificas da medicina foram amplamente discutidas pelos médicos-pesquisadores do Serviço de Saúde do Exército, resultando em um conhecimento voltado para o bem-estar dos soldados em tempo de paz e de guerra, neste contexto de saneamento da população brasileira projetado pelo Estado, a preocupação com a higiene das tropas não poderia ser uma questão deixada de lado pela classe medica do exército. Lembrando que a higiene tem como objetivo a proteção e o desenvolvimento da saúde, evitando dentro do possível a proliferação de doença evitáveis (CARDOSO, 2013, p.25). Trazendo isto para o cotidiano dos militares, os estudos de higiene das tropas levaram em consideração assuntos como educação física militar, fardamento, profilaxia das doenças, alimentação, constituição de fronteiras e a habitação que se encontravam estes soldados (CARDOSO, 2013, p.25).

\section{Referências}

ALVES, Claudia. Participação do Exército na proclamação da República: Revendo a Questão Militar. ANPUH - XXII SIMPÓSIO NACIONAL DE HISTÓRIA - João Pessoa, 2003.

CARDOSO, Rachel Motta. A Higiene Militar: um estudo comparado entre o Serviço de Saúde do Exército Brasileiro e o Cuerpo de Sanidad do Exército Argentino (1888-1930), Rio de Janeiro: [s.n.], 2013.

DIAS, João Carlos Pinto (Org). Clínica e terapêutica da doença de Chagas: uma abordagem prática para o clinico geral. Rio de Janeiro:FIOCRUZ, 1997.

HOCHMAN, Gilberto. A Era do Saneamento: As bases da política de Saúde Pública no Brasil, $2^{a}$ edição, Editora Hucitec, São Paulo, 2006.

LIMA, Nísia Trindade, HOCHMAN, Gilberto. Condenado pela raça, absolvido pela medicina: O Brasil descoberto pelo movimento sanitarista da Primeira República. In: MAIO, Marcos Chor, SANTOS, Ricardo Ventura (Orgs.). Raça, ciência e sociedade. Rio de Janeiro: Fiocruz, Centro Cultural Banco do Brasil, 1996. 252p

LIMA, Nísia Trindade. Um sertão chamado Brasil: Intelectuais e representação geográfica da identidade nacional. Rio de Janeiro. Editora Revan, 1999 
LÖWY, I. Vírus, mosquitos e modernidade: a febre amarela no Brasil entre ciência e política [online]. Tradução de Irene Ernest Dias. Rio de Janeiro: Editora FIOCRUZ, 2006. 427 p. História e Saúde collection. ISBN 85-7541-062-8. Available from Scielo Books.

SÁ, Dominichi Miranda de. A voz do Brasil: Miguel Pereira e o discurso sobre o "imenso hospital”. História, Ciências, Saúde - Manguinhos, v.16, supl.1, jul. 2009, p.333-348.

SILVA, Arthur Lobo da. A luta contra as moléstias venéreas no exército brasileiro. Imprensa gráfica editora Paulo Pongetti \& Cia. Rio de Janeiro.1929

. O Serviço de Saúde do Exército Brasileiro (Historia evolutiva desde os tempos primórdios até os tempos atuais). Rio de Janeiro: Biblioteca do Exército, 1958.

SOUZA, Vanderlei Sebastião de. A política biológica como projeto: A 'eugenia negativa' e a construção da nacionalidade na trajetória de Renato Kehl (1917-1932). Dissertação de Mestrado (História das Ciências), Rio de Janeiro: Casa de Oswaldo Cruz/Fiocruz, 2006 